\title{
واقع استخداه المزيج الترويجي واثرة في تعزيز الميزة التنافسية لشركة فاين لصناعة الورق الصحي
}

\author{
د. عبدالفتاح محمود العزام \\ كلية الاقتصاد والعلوم الإدارية - جامعة الزرقاء - الأردن
}

تاريخ القبول: 2018/2/26

تاريخ الورود: 2017/12/15 (- ت

الملخص

هدفت هذه الدراسة إلى معرفة أثر استخدام عناصر المزيج الترويجي المتمثلة بكافة الأنشطة

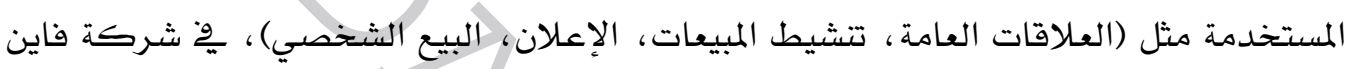

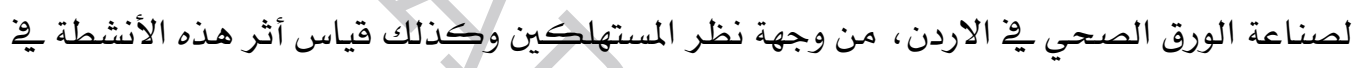

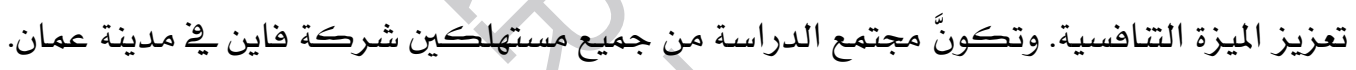

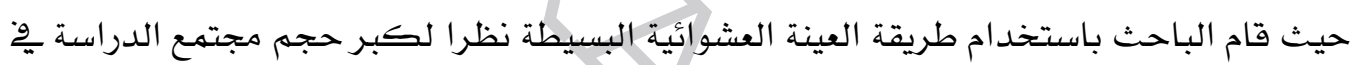

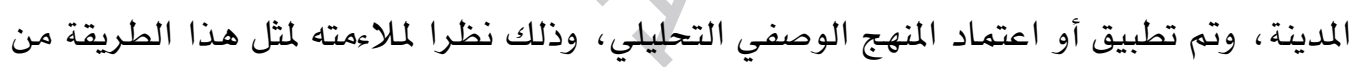

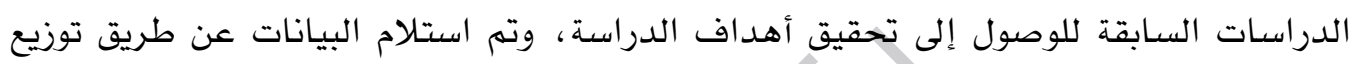

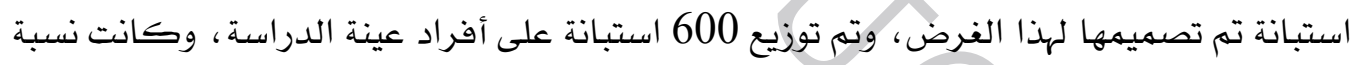

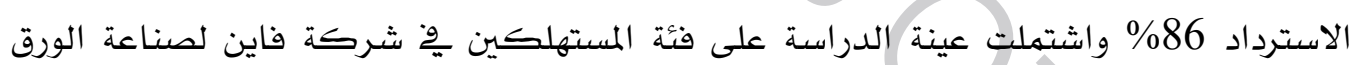

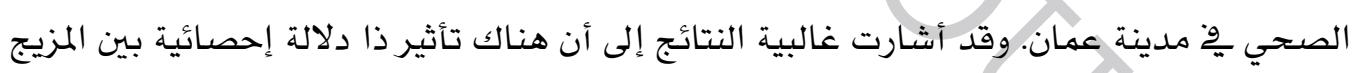

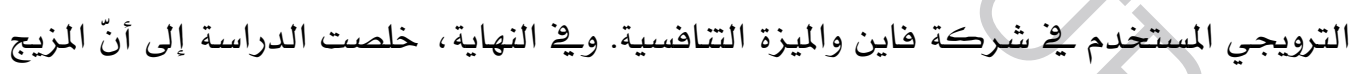

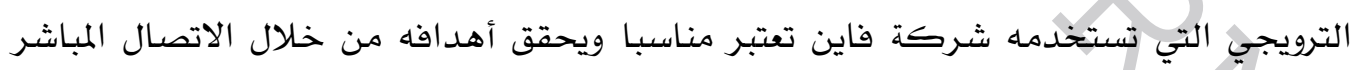
بالمستهلكين من حيث التعدد وِّون طرق ووسائل الترويج المختلفة. الكلمات المفتاحية: المزيج الترويجي، الميزة التتافسية، شركة فاين لصناعة الورق الصحي، الأردن. 


\title{
The Actual Usage of the Promotional Mix Tools and its Effects on Enhancing the Competitive Advantage in Fine Hygienic Paper Company
}

\author{
By \\ Dr. Abdal Fattah Mahmoud Al-Azzam \\ Faculty of Economic and Administrative Sciences \\ Zarqa University - Jordan
}

\section{Abstract}

This research aimed to identify the actual practices of promotion mix tools (advertising, personal selling, sales promotion, and public relations) at Fine hygienic paper company in Jordan from the consumer's point of view. Moreover, the research purposes to measure the effect of these practices to enhance the competitive advantage. The study population consisted of all consumers Fine Company in Amman. The researcher used the random sample in this study. The analytical descriptive technique was used to accomplish the objective of the research, collected data through a survey designed for this research, 600 respondents were distributed and the proportion of recovery was $\% 86$. The sample of this research was chosen from consumers from The Fine Company. The Results showed a statistical impact between promotion mix and the competitive advantage. The study concluded that promotion mix also achieved its goals in terms of direct communication with consumers through different communication and promotion especially electronic through the company's website.

Keywords: marketing mix, competitive advantage, Fine hygienic paper company in in Jordan. 
يعد التسويق من الأنشطة المهمة والحيوية لكافة الشركات بهختلف أنواعها وتخصصاتها ،

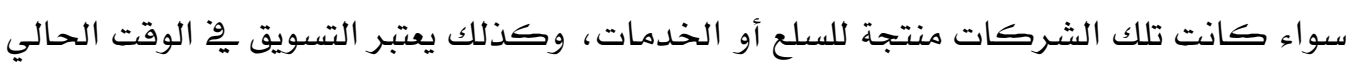

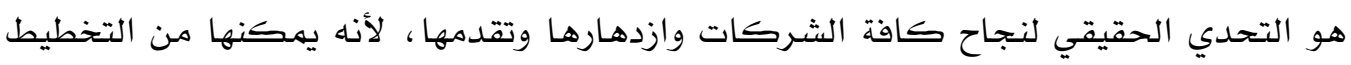

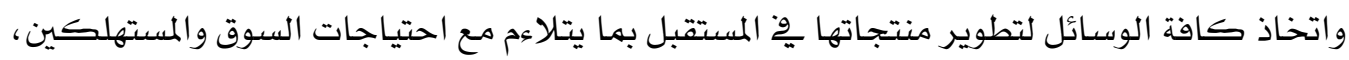
وكذلك يساهم مِّ معرفة الالية لتسعير هذه المنتجات، ويعمل على إيجاد الطريقة المناسبة للترويج للشركات بطريقة علمية وعصرية تتوافق مع السوق المستهدف، وكذلك يعمل التسويق على

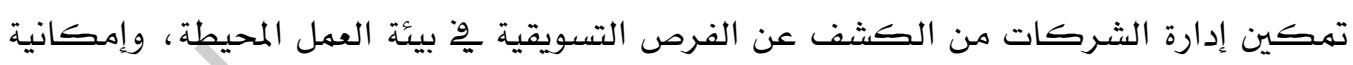

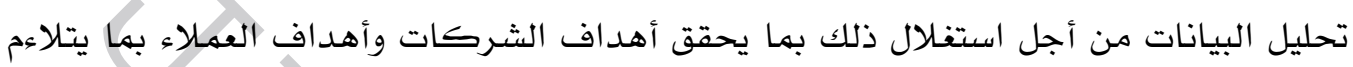

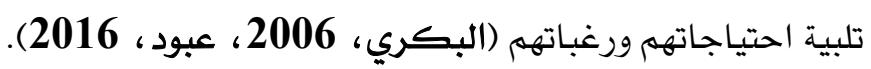
ولوحظ يخ الآونة الأخيرة الاهتمام الزائد من قبل الشركات بعناصر المزيج الترويجي المتمثلة

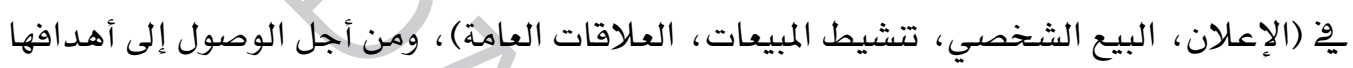

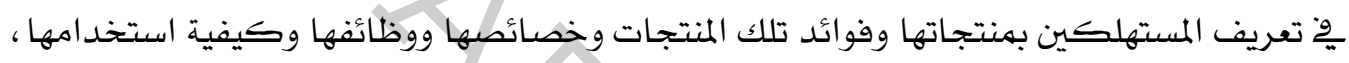
والأماكن الني تتواجد فيها تلك المنتجات وأسعارها، ومن ثم محاولة أقناع المستهلك بشراء تلك وهن المنتجات، وترى الشركات أنه من الضروري أن تؤثر القرارات المتعلقة بالمزيج الترويجي على القنوات التجارية ومن ثم على المستهلك (المصري، 2006، 2006، بوخنون، المتروي، 2013). وللترويج مكانة خاصة ودور مميز ورائد بِّ العملية التسويقية، وتتبع تلك المكانة من وجود

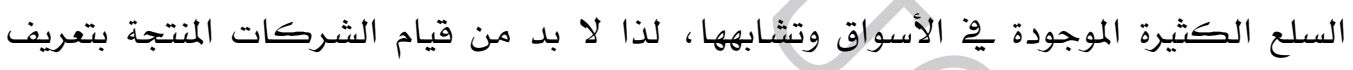

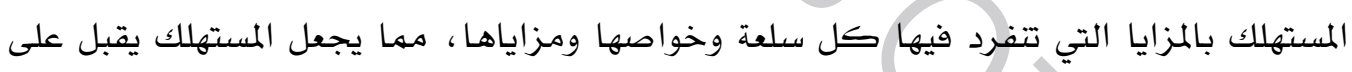
شراء واقتناء هذه السلعة أو تلك. ويقصد بالترويج بانه الجهود التسويقية التي تقوم بها الشركات من أجل إيصال المعلومات عن

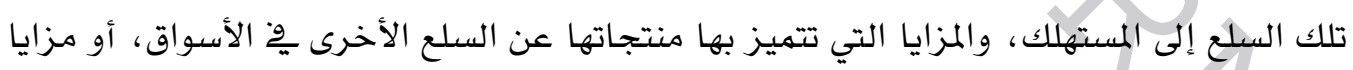

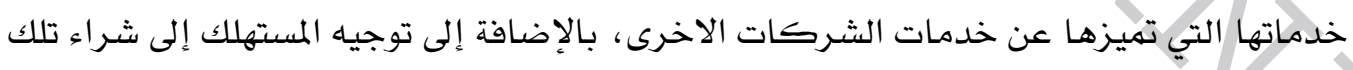

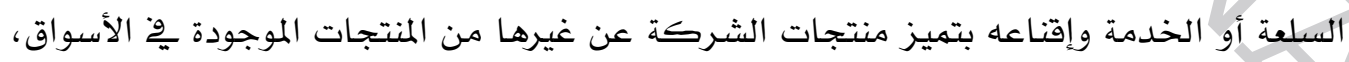

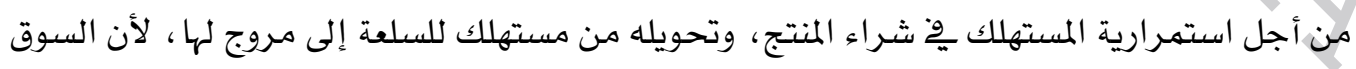

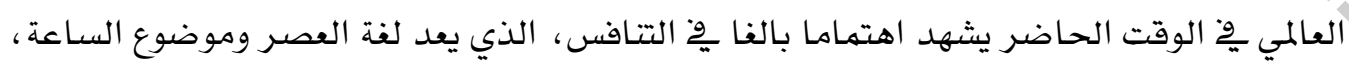

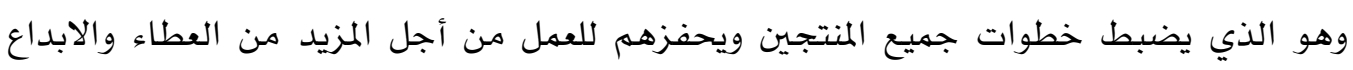


والتميز على منافسيهم وأقرانهم من الشركات الأخرى، وذلك من أجل الوصول إلى أعلى

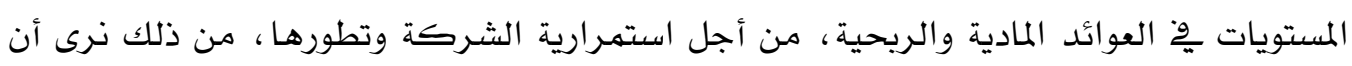
شركة فاين، وقوة منافستها ِِّ الأسواق تكمن ِِّ قدرتها على إنتاج أصناف جديده ومتميزة ومتطورة وذات نوعية جيدة وبأسعار مقبولة مها جعلت المستهلك يقبل على شرائها واستخدامها والترويج لها. ومن هنا عملت شركة فاين من أجل العمل الجاد والمستمر لخلق وإيجاد الميزات التتافسية من أجل تحسين وتطوير موقعها التتافسي يخ الأسواق المحلية والدولية أو مجرد المحافظة

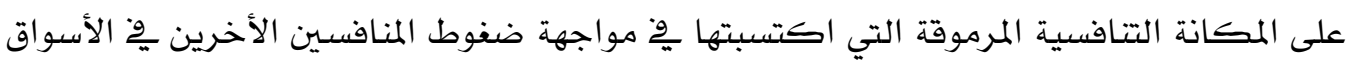

(عبد الهادي، 2018).

مشكلة الدراسة

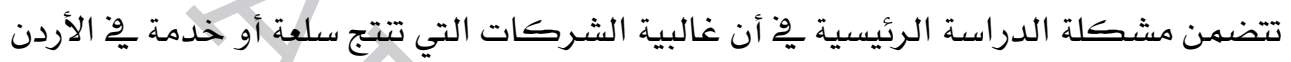

تواجه الكثير من التحديات، ومن أبرزها ضعف الاستراتيجيات الترويجيّة التي لها الدور الكبير مِّ استقطاب المزيد من الزبائن، وكذلك عدم الاهتمام بوضع موازنة خاصة لغايات هذه العهلية، وكذلك ضعف التقنيات أو استخدام التكنولوجيا المتطورة يخ السياسات الترويجية المتمثلة ِو. الإعلان، البيع الشخصي، تتشيط المبيعات، العلاقات العامة ، مها يؤثرّ سلبا على قدرت الشركة وِّ مواجهة التتافسية مع الشركات الأخرى. وبالتالي يمكن تلخيص مشكلة الدراسة ِوْ الإجابة عن السؤال التالي: ما هو أثر الترويج ِِّ تطوير الميزة التتافسية لشركة فاين لصناعة الورق الصحي؟

يندرج تحت هذا السؤال عدة تساؤلات فرعية على النحو التالي: 1- هل الإعلان أثر بِّ تعزيز الميزة التتافسية لشركة فاين لصناعة الورق الصحي؟ 2- هل البيع الشخصي أثر يْ تعزيز الميزة التتافسية لشركة فاين لصناعة الورق الصحي؟ 3- هل تتشيط المبيعات أثر وِّ تعزيز الميزة التتافسية لشـركة فاين لصناعة الورق الصحي؟ 4- هل العلاقات العامة أثر يْ تعزيز الميزة التتافسية لثركة فاين لصناعة الورق الصحي؟ أهداف الدراسة إن الهدف الأسـاسي لهذه الدراسـة يتمثل يخ توضيح الأثر الفعال الذي يلعبه عناصر المزيج الترويجي، والذي يعد من أهم عناصر المزيج التسويقي يخ جعل شركة فاين لصناعة الورق 
الصحي پِّ تحسين موقعها التتافسي بين الشركات المنافسة، وذلك باستخدام استراتيجيات ترويجية تتلاءم مع الظروف المحيطة بها لغرض تحقيق الأهداف. 1- التعرف إلى أثر الإعلان يْ تعزيز الميزة التسافسية لشركة فاين لصناعة الورق الصحي. 2- بيان أثر البيع الثخصي يْ تعزيز الميزة التتافسية لشركة فاين لصناعة الورق الصحي. 3- الكشف عن تشيط المبيعات يوّ تعزيز الميزة التنافسية لشركة فاين لصناعة الورق الصحي. 4- إظهار أثر العلاقات العامة فِّ تعزيز الميزة التتافسية لشركة فاين لصناعة الورق الصحي.

أهمية الدراسة

تتمثل أهمية البحث ِّخ كونها تعالج موضوعا حديثاً ومتطوراً ونادراً ما تحدث عنه العلماء والكتاب مقارنة لما له من أهمية كبيرة، لأنه يعد حديث الساعة حيث إنها تعالج مشكلة حقيقية وهي استراتيجية الترويج ِِخ ظل بيئة الأعمال الحالية التي تعاني من العديد من التغيرات والتحولات البيئة السريعة المختلفة ، ولعل أهم هذه التحولات هي العولمة التي أدت إلى تحرير التجارة العالمية وفتح الأسواق أمام جميع المنتجات وإزالة الحواجز ما بين الدول مها جعل شركة فاين تواجه منافسة عالمية قوية ليس وِّ الأسواق الخارجية فحسب، وإنما أيضا ِِّ الأسواق المحلية الذي ستدخله منتجات أكثر جودة من المنتجات الوطنية، اتبّاع المسوقين لها أسـاليب ترويجية متقدمة، لهذا يتطلب من شركة فاين تطوير استراتيجيتها الترويجية وإتباع أساليب ترويجية حديثة تمكنها من ضمان مركزهـا التتافسي يخّ السوق.

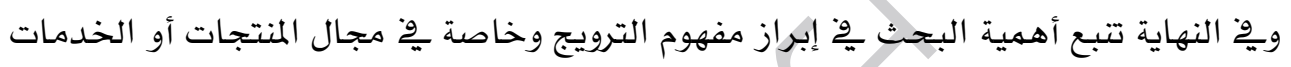

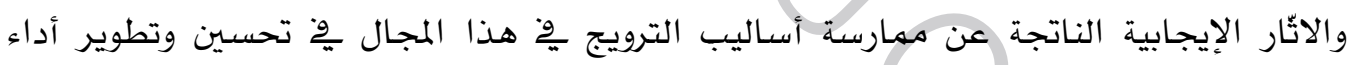
الشركة وتوسيع موقعها التتافسي من كونها تحقق الفوائد لأكثر من طرف لأفئه فرضيات الدراسة استتادل إلى مشتكلة الدراسة وأهدافها ، وأهميتها، التي تم اعتمادها مسبقا قام الباحث بصياغة الفرضية الرئيسية التالية: الفرضية الرئيسية الأولى: : لا يوجد تأثير ذو دلالة إحصائية عند مستوى الدلالة (a (a 0.05 بين المزيج الترويج وتعزيز الميزة التنافسية لشركة فاين لصناعة الورق الصحي ويتفرع من الفرضية الرئيسية الفرضيات الفرعية الاربعة الاتية: 
Ho1 لا يوجد تأثير ذو دلالة إحصائية عند مستوى الدلالة (a (a) ، بين الإعلان وتعزيز الميزة التتافسية لشركة فاين لصناعة الورق الصحي

: Ho2 لا يوجد تأثير ذو دلالة إحصائية عند مستوى الدلالة (a (a) ، بين البيع الشخصي وتعزيز الميزة التنافسية لشركة فاين لصناعة الورق الصحي

Ho3 : لا يوجد تأثير ذي دلالة إحصائية عند مستوى الدلالة (a 0.05 ) ، بين تتشيط المبيعات وتعزيز الميزة التتافسية لشـركة فاين لصناعة الورق الصحي Ho4: لا يوجد تأثير ذو دلالة إحصائية عند مستوى الدلالة (5 a 0.0 a ، بين العلاقات العامة وتعزيز الميزة التتافسية لشـركة فاين لصناعة الورق الصحي

\section{أنموذج الدراسة}

تكون أنموذج البحث الحالي من متفيرين اثنين، متغير مستقل يشهمل عناصر المزيج الترويجي المتهثل (الإعلان، البيع الثخصي، تتشيط المبيعات، العلاقات العامة) ومتغير تابع هو تعزيز الميزة التتافسية، والذي يساعد الافتراض لأن الترويج له علاقة ودور ِخْ تدعيم تعزيز الميزة التتافسية وذلك أن تطبيق المزيج الترويجي يِ شـركة فاين يتضمن معرفة مسبقة حول قوى التـافس الخمس، وأن تعزيز الميزة التتافسية يخ الشـركة يتطلب توفر معرفة وإدراك حول القوى المنافسة المحيطة وِي الشركة ، ويبين الشكل رقم (1) انموذج الدراسة.

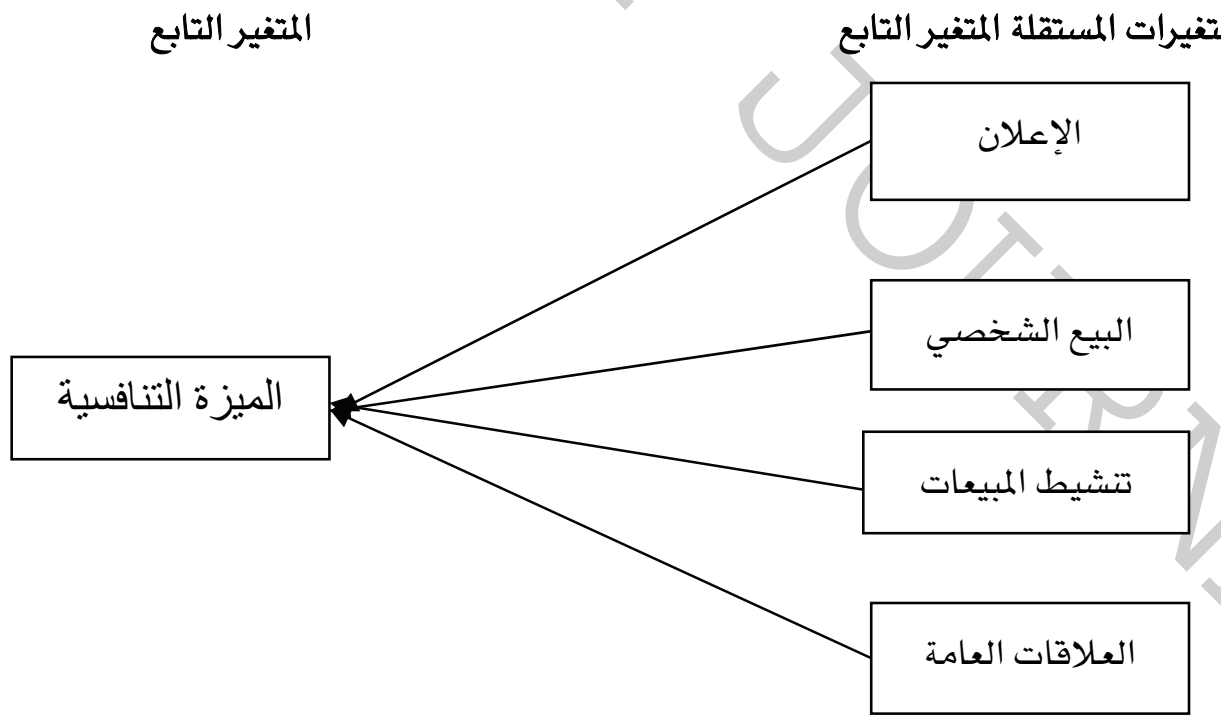

شكل رقم (1) أنموذج الدراسة. 
الإطار النظري والدراسات السـابقة

الترويج

يعد الترويج من العناصر المهمة واللازمة بل الضرورية للشركات المعاصرة سواء كانت تختص بالإنتاج أو تقديم الخدمات، لأن التسويق يحظى بمكانة خاصة وضرورية لكل من المنتج والمستهلك، ويعد التسويق المرحلة الوسطى بين الإنتاج والاستهلاك لا يمكن لأي شركة النجاحِّ. بيع وتعريف منتجاتها وتحقيق أهدافها دون اللجوء إلى هذا العنصر المهم من عناصر المزيج الترويجي وهو التسويق وكذلك المستهلك لا يهكن لله أن يشبع رغباته وقناعاته دون عملية الترويج الذي يعرفه بالمنتج بطريقة مناسبة وسعر يستطيع تحمله، ويعد عنصر الترويج من العناصر الضرورية ِِّ المسائل الإدارية لأنه يعد ِِّ حلات القوة الدافعة للنشاط التسويقي والعامل الأكثر تأثيراً وحسما يوّ تعريف بعض السلع والخدمات ولأهمية هذا العنصر فإن هنالك من يرى بالاتحاد أو المسـاواة بين مفهوم التسويق والترويج مصطلحان لشيء واحد ، والرغم من خطأ هذا التعريف فإن محاولة وضع الترويج والتسويق بنفس المفهوم يشير إلى الأهمية البالغة التي توليها بعض المنظمات للنشاط الترويجي (بوخنون، 2013)

مفهوم الترويج

كلمة الترويج باللغة العربية تعني راج الشيء أي تعاطاه الناس وشـاع فيما بينهم، وهذا يعني أن الترويج هو طريقة الاتصال والتواصل مع الآخرين وتوضيح لهم بجميع أنواع السلع والخدمات التي تتتجها الشركة (منال، 2007). وهناك تعريفات عدة للترويج وذلك حسب ما تحدث عنه كثير من علماء التسويق، إلا أن كل التعريفات تصب يٌْ مفهوم واحد ، ويمكن التطرق إلى أهم تلك التعريفات يٌ الوقت الحالي، فقد عرف (البكري، 2006) الترويج على أنه التسيق بين كافة الجهود التي يستطيع أن يبذلها البائع يو إقامة منافذ لكافة المعلومات التي تسهيل بيع السلع والخدمات أي قبول فكرة معينة. أها (Kotler, \& Keller, 2006) فقد عرفة على أنه (يهثل عملية الاتصال بالآخرين وتثتجيعهم وتعريفهم بالمنتج وحثهم للحصول عليه وبالتالي تتشط الطلب وزيادة المبيعات وتحقيق الأرباح للشركة ويتم بوسائل الاتصال المختلفة)، أما ناصر (2006) فقد عرف الترويج على أنه (عملية تعريف المستهلك بالسلعة أو الخدمة التي تركز على خصائصها ووظائفها ومزاياها وكيفية استخدامها وأماكن وجودها بالسوق)، بالإضافة إلى محاولة التأثير على جذب انتباه المستهلك وإقناعه بشراء تلك المنتجات أو الخدمات لذلك الشركة. 
ويخ الختام الترويج هو عملية اتصال يهدف إلى إقتاع وتأثير على جذب انتباه المستهلكين بهنتجات الشركة ودفعهم لشراء تلك المنتجات أو الخدمات لتلك الشركة وهو يهثل العامل الرابع من عناصر المزيج التسويقي والأهم من ذلك حيث إنه يتسبب سوء إدارته ِِّ فثل الشركة ِِّ إيجاد علاقات جيدة مع الأطراف الأخرى المنافسـة.

أهمية الترويج

أظهر يٌْ بيئة الأعمال يْ الوقت الحاضر الدور الكبير الذي يلعبه الترويج والحاجة الماسـة إليه لما لله أثر فعال يٌْ بقاء الثركة وازدهارها، فهو المفتاح الأساسي لاتفتاح أبواب التطور والركيزة الرئيسية ِِّ نشاط الأعمال، وقد ظهرت أهمية النشاط الترويجي بشكل كبير خاصة ِِّ تلك الشركات التي تواجه أجواء تتافسية كبيرة، وقد تزايد أثره الاستراتيجي خلال القرن الحادي والعشرون نتيجة للثورة الهائلة ِِّ مجال تطور الاتصالات التي حولت العالم إلى قرية كونية صغيرة بالإضافة إلى أذواق وقدرات الزبون التي تتفير بسرعة وكذلك اتجاه معظم بيئة الأعمال الدولية نحو الأسواق الحرة وانتقالهم من أعمال منتظمة ومدروسة إلى أعمال السوق (المصري، 2006). وتظهر أهمية الترويج لتقريب المسافة بين المنتج والمستهلك، لذا يتطلب ذلك وجود وسائل أخرى تساهم يو تقريب وجهات النظر والاتصال بين المنتج والمستهلك وكذلك المنافسة الثديدة بين المنتجين يُّ السوق، لذلك يتطلب القيام بجهود ترويجية كبيرة من أجل كسب المعركة والثبات

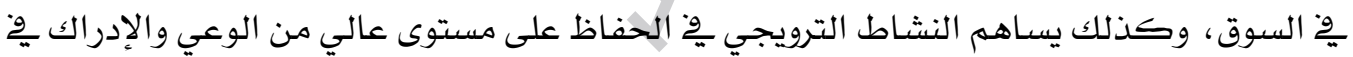
حياة المستهلكين، من خلال ما يفيدهم به من معلومات وبيانات كاملة عن جميع كل ما يتعلق بالمنتجات والخدمات التي تقيد المستهلك (قاقي، 2015، منال، 2007)

أهداف الترويج

هنا نلاحظ أن الترويج يحاول استهداف مشكلة جهل أو عدم معرفة الزبون من خلال تقديمه معلومات عن منتجات الثركة وعلامتها التجارية والأسعار، وكذلك يقصد به إغراء المستهلك وِ2 إيجاد حالة نفسية معينة يحاول ارضاء البائع. ويرى (Kotler) أن التجاوب لأية عملية ترويج التي تعتمد على عنصرين هما الشراء والقناعة، لأن الهدف الأساسي من عملية الاتصال هو معرفة المتصل وكيف يحول اتجاه أنظار الجمهور المستهدف إلى حالة يكون فيها جاهزاً اشراء المنتجات أو الخدمات (Kotler, 2004). وعليه يهكن أن يتحقق هدف الترويج من خلال تزويد الزيون الحالي والمستقبلي بالمعلومات عن المنتجات، وهذا من الأهداف المهمة خاصة عند تقديم المنتجات الجديدة، لأن ِِّ ذلك تعريف الزبون بالمنتجات الجديدة مها يشتجعّه على تجريتها ، وكذلك إثارة 
اهتمام الزيون بالمنتج، وخاصة عندما تكون هناك منتجات أو خدمات جديدة أخرى منافسة ِِّ

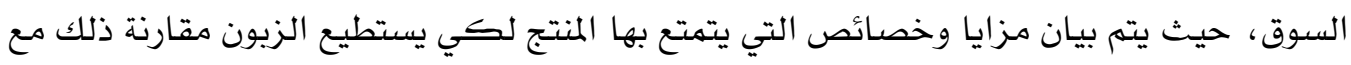

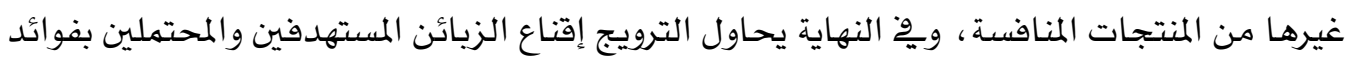

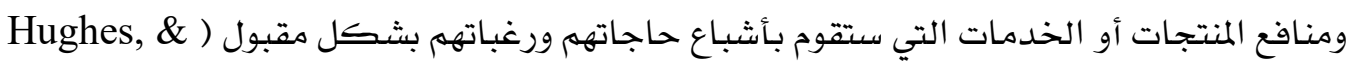

.(Fill, 2007

عناصر المزيج الترويجيّ

تعرف بأنها "مجموعة التقنيات الترويجية التي تستخدمها الشركة لبيع منتجاتها وخدماتها"، يجب أن تكون عناصر المزيج الترويجي متكاملة مع أساسيات التسويق حتى لا تصل معلومات

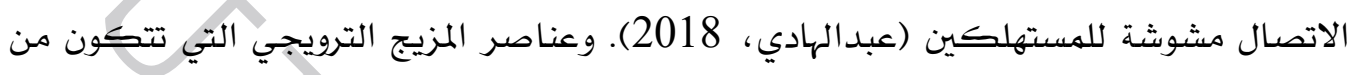

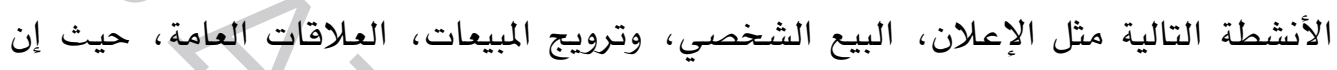

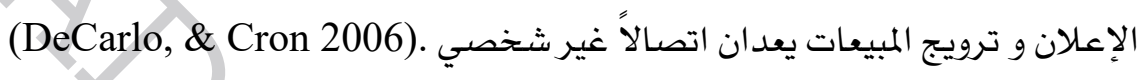

الإعلان

يعتبر الإعلان من أهم مكونات المزيج الترويجي ڤِ مجال التسويق، لأن الزبون ِِّ هذا العصر

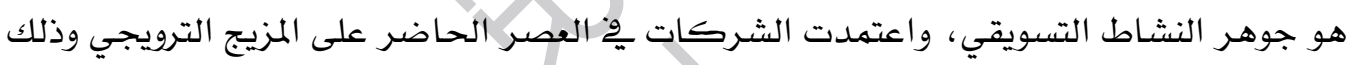

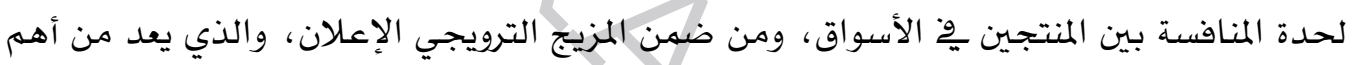

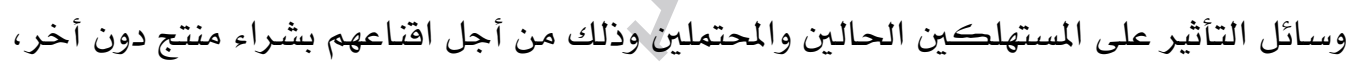

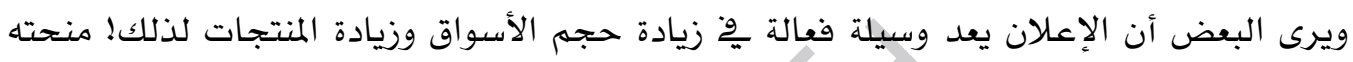

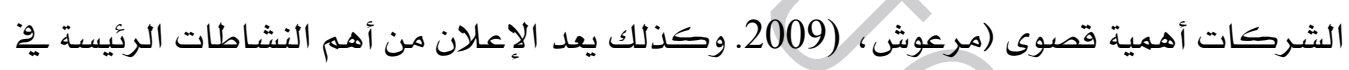

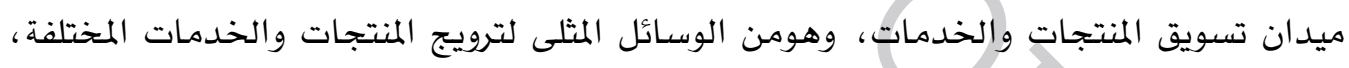

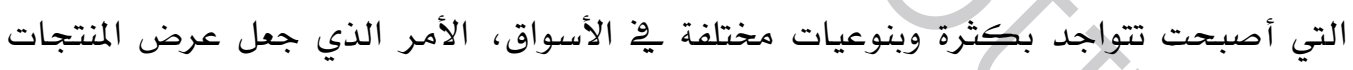

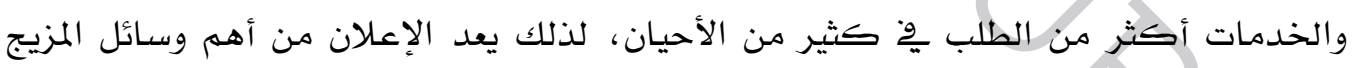
الترويجي الذي يؤدي إلى نجاح الشركات لتحقيق أهدافها التسويقية والترويجية المختلفة باعتبار

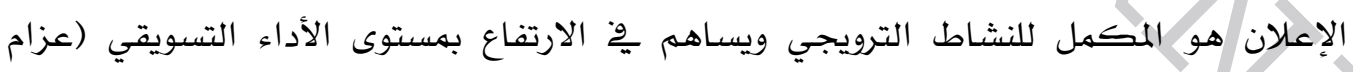

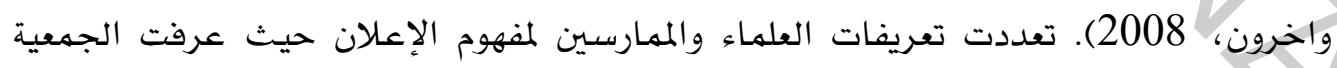

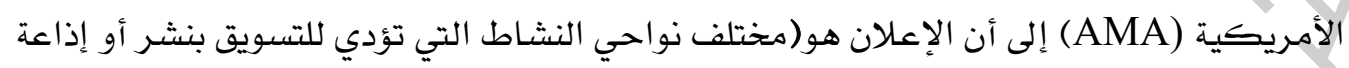

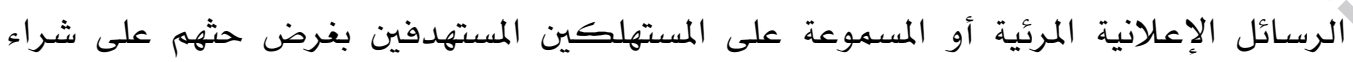

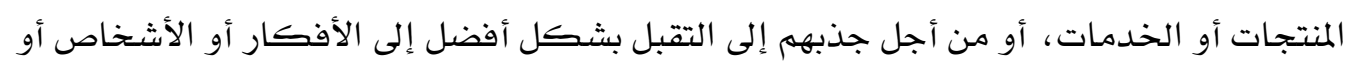


الثركات المعلن عنها). كمها أوضح عبد الهادي وآخرون (2011) إلى أن" الإعلان هو ذلك

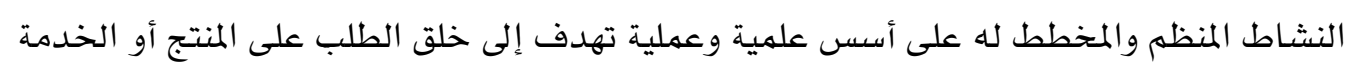
أو الفكرة وإثباعه مقابل أجر مدفوع، وذلك من خلال وسائل الإعلام المختلفة بشرط مراعاة كافة الضوابط الفنية والشكلية المتأثرة والمؤثرة فيه لإحداث الأثر الإيجابي يخٌ الجههور المراد مخاطبته." وعليه فإن الباحث يستطيع أن يعرف مفهوم الإعلان على أنه عبارة عن أداة اتصال غير شخصية ومدفوعة الأجر، لإيصال معلومات كاملة عن المنتجات من خلال معلن معين إلى جمهور

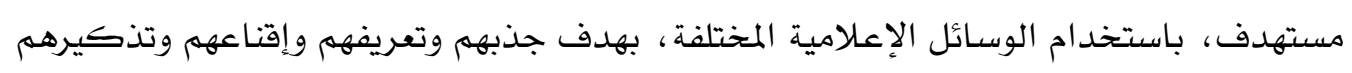
لثراء هذه المنتجات وتعزيز ثقة المستهلكين الحاليين والمرتقبين بالشركات، وبالتالي زيادة حجم المبيعات وأرباح الشركات.

\section{العلاقات العامة}

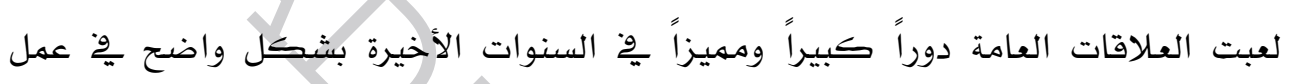
الشركات، وكثير من الشركات اعتمدت بشكل مباشر على هذا النشاط! وذلك لأن العلاقات

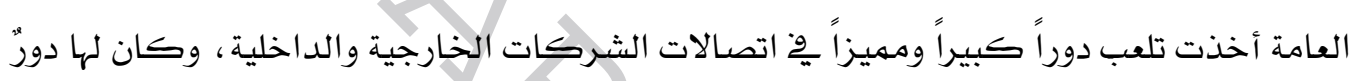
كبير" يوٌ علاقاتها بهجمل الشركات. ولم تعد العلاقات العامة حكراً على شركة معينة أو مجال معين، بل اعتمدتها الشركات العامة والخاصة على حد سواء ِخ مختلف أشكالها وتتظيماتها (Pettitt, \& Brassingtun,2005). وتعد العلاقات العامة جزءًا لا يتجزاً من مجهودات الاتصالات الكاملة فِ السوق إلى جعل الشركة تتمتع بصورة حسنة والإبقاء على هذه الصفة أو الصورة بشكل دائم، وتعد الجسر الذي يصل بين الشركة وجهاهير زبائها ، لذلك ظهر مفهوم العلاقات العامة والهدف منها إقامة علاقة طيبة بين الشركة وزبائنها والعمل على إقامة تلك العلاقة الحسنة وإيجاد الثقة المتبادلة بين الثركة وزبائنها (البكري، 2006). ويمكن تعريف العلاقات العامة على "أنها النشاط المخطط الذي يهدف إلى تحقيق الرضا والتقاهم المتبادل بين الشركة وزبائنها، سواء كان داخليا أو خارجيا من خلال استراتيجيات وبرامج تعتمد بو. تتفيذها على الأخذ بهبدأ المسؤولية الاجتهاعية" (الضمور واخرون، 2008). وِوْ النهاية فالعلاقات العامة هي عبارة عن إقامة علاقات طيبة مع جميع المستهلكين، ولكي يتمكن الممارسون من تحقيق أهد افهم هذه يجب ان يكون لديهم معلومات كافية ودقيقة ومفصلة عن طبيعة المستهلك، وذلك من خلال إعداد برنامج محكم لجميع المعلومات والاتصال المستمر بكافة الجمهور المستهدف بهدف إعداد خطه وسياسة العلاقات العامة على أسـاس متطلبات الفعلية للشركة. 
البيع الشخصي

البيع الشخصي يعتبر طريقة مهمة لتسويق كافة منتجات الشركات بصفته أحد أنشطة المزيج الترويجي وهذا النشاط يقوم على الاتصال المباشـر بين الشركة أو البائع والمشتري بحيث يؤثر على قرار الشـرائي للمستهلك من أجل شراء المنتج، وللبيع الشخصي طرق عدة منها المواجهة المباشـرة بين البائع والمشتري، ومنها الاتصـال الهاتقي من خلال الشبكات الحاسوبية أو من خلال شبكة الانترنت (احسن، 2009). ويعد البيع المباشر بين المنتج والمستهلك من أساليب الاتصال الثخصية التي تعتمد أسـاساً على الجهد الذي يقوم به البائع من أجل إتمام الصفقة بينه وبين الزبون أو المستهلك، وذلك عن طريق قيام المنتج بإقناع الزبون بفوائد ومميزات السعة التي تجعله يقدم على الشراء مباشرة، وهناك الكثير من المصطلحات والمترادفات والتعريفات للبيع الثخصي نذكر منها على سبيل المثال لا الحصرً قوة البيع "و تعرف بأنها العملية المتعلقة بتزويد كافة الزبون بالمعلومات و إقناعه بشراء تلك السلعة أو الخدمة من خلال البيع الشخصي يِّ موقف تبادلي، و تتشكل قوة البيع من مجموع المستهلكين المكلفين بالبيع و دراسة الطلب و محاولة التأثير عليه إيجابا" (توفيق، 2005). أما البيع الثخصي كها عرفته الجهعية الأمريكية للتسويق " يهثل كافة الجهود الشخصية الموجهة إلى المستهلكين بهدف حثهم واقناعهم على القيام بشراء

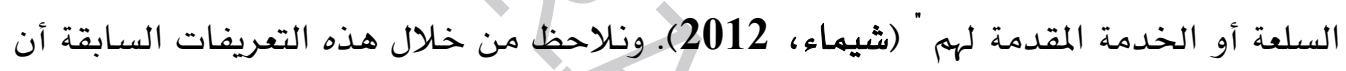
الأسـاس الذي يركز عليها مفهوم البيع الشخصي، تتشكل يخ توفير المعلومات الشاملة لمستهلكين منتجات الشركة لإثارة دوافعه وحاجاته غير المشبعة ثم محاولة التأكيد الرغبة لدياه، للوصول إلى إقناعه بشراء هذه السيلع، اعتمادا على الاتصالات الشخصية بين رجل البيع وجههور المستهلكين المحتملين. تتشيط المبيعات يعد تتشيط المبيعات أحد العناصر الضرورية والمهمة ِخ المزيج الترويجي الذي حظي بهكانة مرموقة موْ الآونة الأخيرة من قبل الإدارات التسويقية، حيث كان الإعلان هو العنصر الرئيسي يوِ المزيج الترويجي لسنوات طويلة لأن الكثير من الشركات ركزت على هذا العنصر كأسلوب ترويجي لكي تستطيع من خلاله الترويج للمنتجات أو الخدمات المعلن عنها ، وبناء الصورة الذهنية المناسبة عند المستهلكين من أجل الوصول إلى ولاءات استهلاكية، ولكن مِّ السنوات الأخيرة أدركت الكثير من الشركات أن المبالغ التي تتفق على الإعلان لا تكفي لتحقيق أهداف الشركات المنتجة ، ومن هنا بدأ اهتمام الشركات يتجهه نحو وسائل اخرى غير الإعلان لكي يتم 
بوساطتها زيادة ترويج مبيعاتها على كافة المستويات لذا لجأت بعض الشركات إلى زيادة حجم انقاقها لعنصر أخر وهو تنشيط المبيعات على حساب ما كانت تخصصه يوّ نققات لعنصر الإعلان، حيث ذكر مالك احدى شركات الإنتاج أنه كان يخصص مبلغ قيمة 70\% من ميزانية

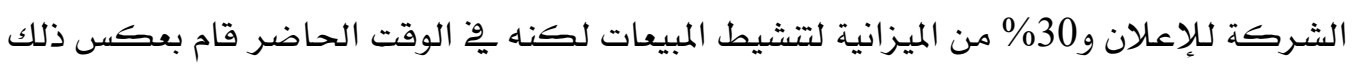

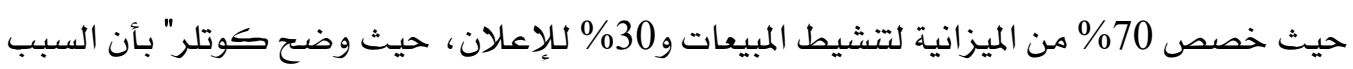
الذي يعود إلى ذلك أن تأثيرات الإعلان على المستهلك تحتاج إلى وقت أطول من تأثيرات تتشيط

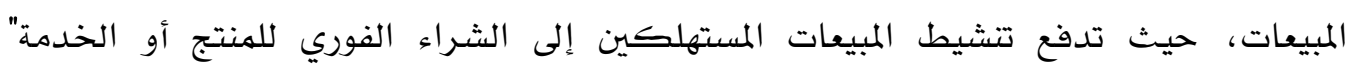
(احسن، 2009، ابو فارة، 2005). وهناك الكثير من التعريفات لتتشيط المبيعات التي ذكرها علماء الاقتصاد الممارسـين لمجال التسويق كل حسب رأيه، حيث عرفها فيليب كوتر (2006) بأنها : "مجموعة من التقنيات الحديثة الموجهة للتأثير على الطلب يٌٍ المدى القصير، وذلك برفع وتيرة أو مستوى المشتريات لسلعة أو خدمة منجزة من طرف المستهلك أو الوسطاء التجاريين." وعرفتها أمينة (2012) بأنها " كافة الأسـاليب الهادفة والموجه لتشيط المبيعات عن طريق ترغيب فئات المستهلكين يِّ الأسواق المستهدفة على زيادة مشترياتهم من السلع أو الخدمات.

ومن خلال تحليل التعريفات السابقة يمكن القول: إن تتشيط المبيعات تتكون من مختلف الأنشطة التسويقية التي تستهدف جذب سلوك المستهلك لمنتجات الشركة ومحاولة دفعه إلى شراء تلك المنتجات خلال فترة زمنية قصيرة باستخدام أنواع مختلفة للتحفيز، والتي تضفي قيمة إضافية على السلعة. الميزة التتاضسية إن نجاح أي شركة يعتمد اعتماداً كاملاً على ميزتها التتافسية ومدى قدرتها بالتأثير على أداء المنافسين وسلوك المستهلكين واختلف الباحثون حول كيفية ذلك كل حسب طريقة تعريفه للميزة التتافسية، حيث تتقسم الآراء إلى قسهـين القسهم الأول: يهتم بالمحيط الخارجي للشـركة من خلال التركيز على ضعف المنافسين، والقسم الثاني: يركز على قوة الشركة كمنطلق لهذه الميزة وذلك باستخدام الإمكانات الداخلية المتوفرة للشركة وبالرغم من الاختلاف يِّ المبدأ الذي قامت عليه هذه التصورات، فإنها تجمع أن حتمية الموقع تعطي للشركة أفضلية تتافسية، وذلك إذا استطاعت أن تعرض منتوج أفضل من تلك الموجودة يُّا السوق وبتكلفة أقل أو اقتراح اختيارات

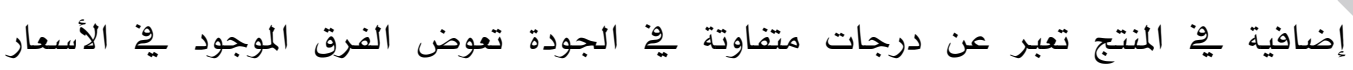
(منال، 2007)، وهناك عدة خلافات بين الكتاب والممارسين حول مفهوم التتافسية باختلاف 
مكان السوق، فمثلا، فيما إذا كان تتكلم عن شركة إنتاجية أو قطاع معين أو دولة معينة، فمفهوم التنافسية الذي تستخدمه الشركة تعني الاستمرار بِّ الحصول على كسب حصة سوقية اكبر وِّ السوق المحلي أو الدولي، وهي تختلف عند الحديث عن مفهوم التتافسية ِِّ القطاع الذي

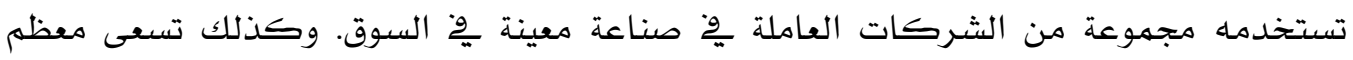

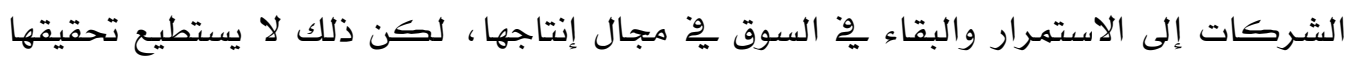
بسهولة بل تواجه غالبية الشركات منافسة شديدة وقوية، ومن أجل تجنب تلك المنافسة ولتحقيق

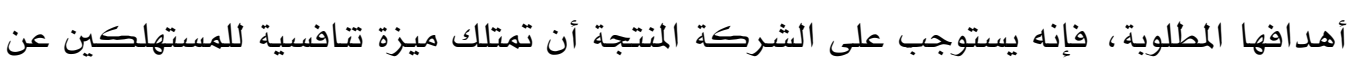
غيرها من الشركات المنافسة، وعليه فمفهوم الميزة التتافسية يهثّل ثورة حقيقية وِّو إدارة الأعمال

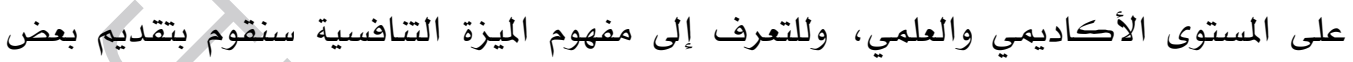

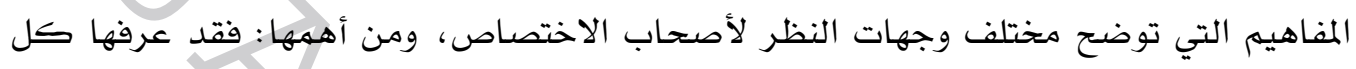

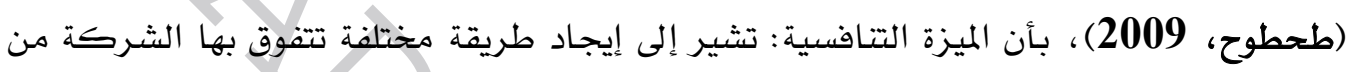

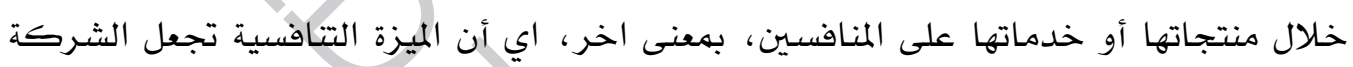

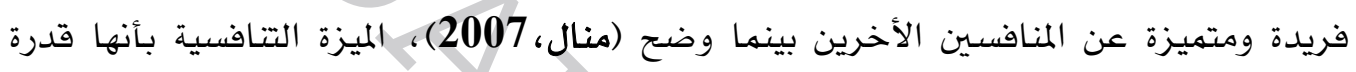
الشركة على تقديم قيمة أو فائدة مميزة للزبون باستهرار، مقارنة مع القيمة أو الفوائد التي ولئي تقدمها الثركات المنافسة.

من خلال المفاهيم التي تم ذكرها سابقاً يمكننا الحديث بأن الشركة تمتلك ميزة تتافسية

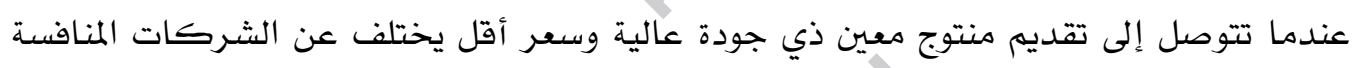

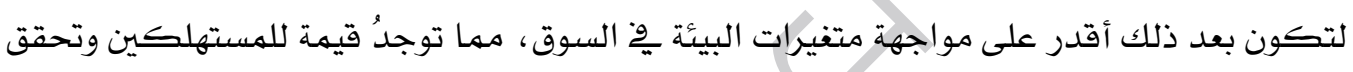

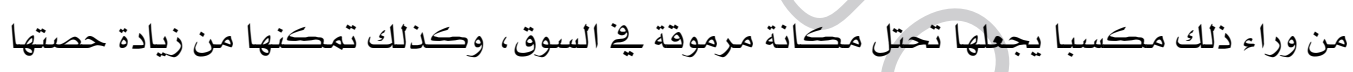
السوقية وتحقيق أرباح تضمن لها البقاء والاستمرار.

الدراسات السابقة 1. دراسة منال (2007) بعنوان دور استراتيجية الترويج ِِّ تحسين القدرة التافسية للمؤسسة الوطنية الجزائرية.

هدف البحث إلى التعرف على الدور الكبير الذي يلعبه الترويج كأهم عنصر من عناصر

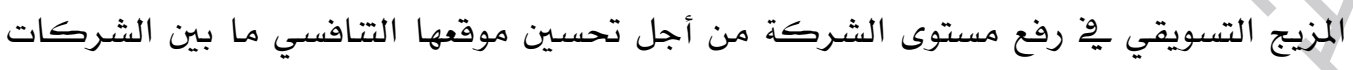

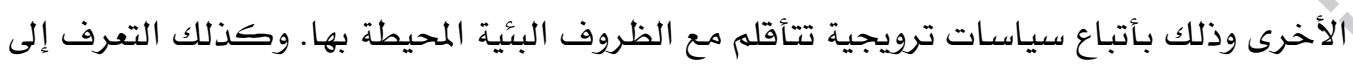
أثر استراتيجية الترويج يوّ تطوير القدرة التنافسية للشركة الوطنية من خلال تحليل العلاقة ما بين 
أثر الترويج وحجم النشاط العام للشركة والعهل على معرفة هذه العلاقة للتوصل إلى منهجية صحيحة تؤدي إلى زيادة تسويق منتجات الشركة. وأظهر البحث إلى مجموعة من النتائج من أهمها ، أن العملية الإنتاجية لا تكفي وحدها لتحقيق المنافع الإجهالية سواء للمستهلك النهائي أو

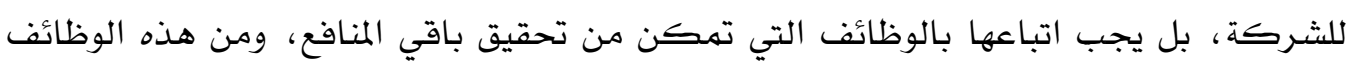
النشاط الترويجي الذي أصبح له أهمية كبرى پِّ الشركة بشكل خاص من باقي العناصر الأخرى، بسبب المنافسة القوية بين المنتجات، إن الشركة التي تقوم بمتابعة ومراقبة بيئها التسويقية التتافسية ودراسة التغيرات التي تحصل فيها ، يمكنها ذلك من إدخال استراتيجية ترويجية تتأقلم مع التغيرات التي تحصل بين الشركات المنافسة مها يؤدي إلى زيادة قدرتها التتافسية ويكسبها ميزة تتافسية.

\section{2. احمد رزق الله (2012) بعنوان أثر الترويج على سلوك المستهلك النهائي}

هدف البحث إلى الكتشاف المزيج الترويجي لمجموعة من الوظائف المتككاملة من خلال

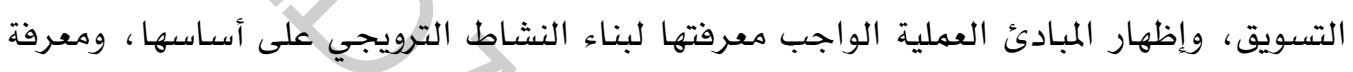

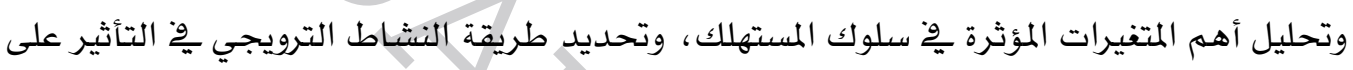
السلوك الاستهلاكي للأفراد. وقد استخدم الباحث وِخداسته المنهج الوصفي التحليلي. وتوصلت الدراسة إلى كثير من النتائج من أهمها، إن الترويج من أهم عناصر المزيج التسويقي ِوِ الشركات الحديثة ، فهو يعمل على زيادة مبيعات منتجات الشركة. بذلك توصل البحث إلى عدَّة توصيات من أهمها الاهتمام بالمستهلك وجمع معلومات عن رغباته وحاجاته وذلك عن طريق إجراء بحوث ودراسـات متكررة.

3. ابو عمرة، رامي (2011) بعنوان واقع الممارسات الترويجية لشركات التأمين ِِّ قطاع غزة وأثرها على رضا العملاء.

هدف هذا البحث إلى محاولة التعرف على أثر الممارسـات الترويجية المتمثلة بالأنشطة التالية (الإعلان، البيع الشخصي، العلاقات العامة، تتشيط المبيعات، الترويج المباشر) على شركات التأمـين العاملة وِخ قطاع غزة من وجهة نظر العهلاء وتحليل معرفة هذه الأنثطة على رضا الزبون، بعد ذلك تم اعتماد المنهج الوصفي التحليلي لتحقيق أهداف البحث، وبعد ذلك، تم جهع البيانات من خلال استبانة البحث التي تم تصميمها لهذا الهدف، وتم توزيع 270 استبانة على هجتمع الدراسة وكانت نسبة الاسترداد \% 94، وكانت عينة الدراسة التي تم استخدامها على فئة

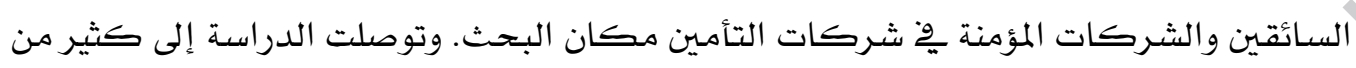
النتائج من أهمها : هناك قصور ملفت للنظر بشكل واضح ِّْ استخدام الأنثطة الترويجية بشكل 
عام پِّ جميع شركات التأمين، ولاحظ أن استخدام أنشطة الإعلان بدرجة متوسطة ِِّ شركات

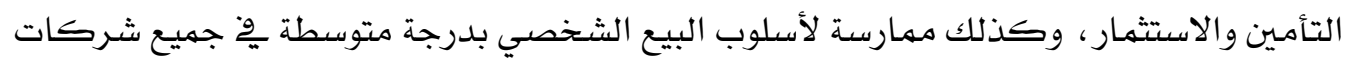

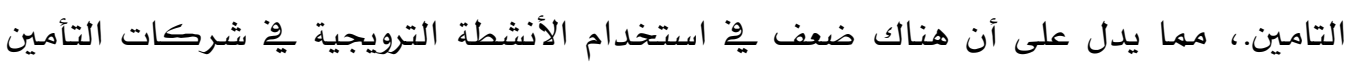
بشكل عام.

4. عبود، حسن، (2016) بعنوان دور عناصر المزيج الترويجي بِّ التخفيف من الاثار السلبية للأزمات على المنتج السياحي، دراسة ميدانية على المنتج السياحي يُّ محافظة اللاذقية. هدفت الدراسة إلى معرفة تقييم العلاقة بين تطبيق عناصر المزيج الترويجي ٍِّ الشركات

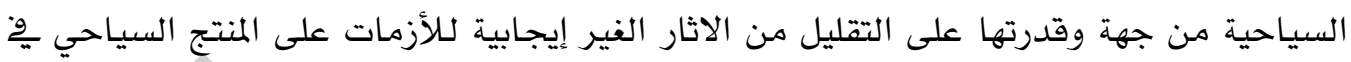

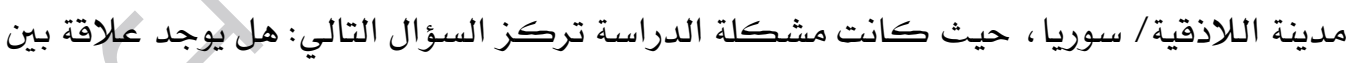

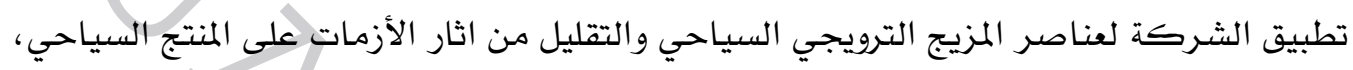

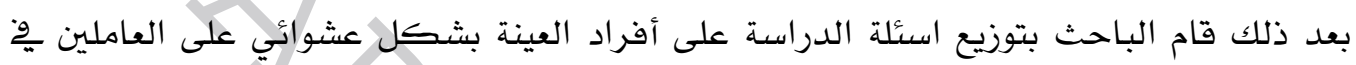
الشركات السياحية على اعتبار أن الموظفين هم زبائن داخليين، وتكونت العينة العينة من 60 استبانة.

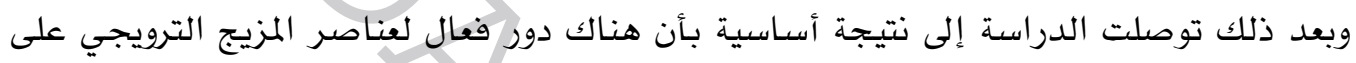
أزمة المنتج السياحي، وكذلك توصل الباحث إلى وجود علاقة مباشرة أنشطة الترويج وقدرتها على التخفيف من أثار الأزمات التي تشمل المنتجات السياحية فِّ مدينة الللاذقية. 5.عبدالهادي، حسني (2018)، أثر استراتيجيات الترويج ِوْ تحقيق الميزة التتافسية (دراسة تطبيقية على المستشفى الاسـلامي/عمان/الاردن).

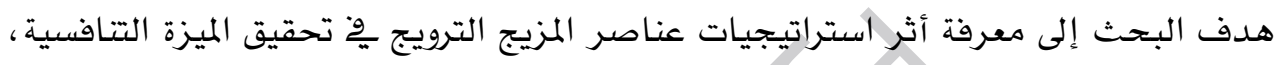

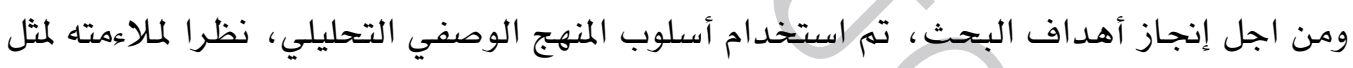

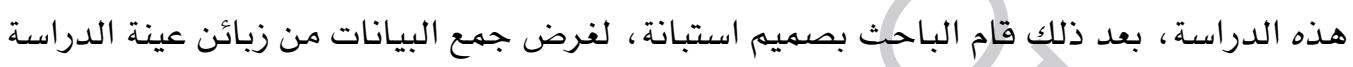
بشكل عشوائي. قام الباحث بعد ذلك بتوزيع (436) استبانة على زبائن المستشفى الاسلامي الذي الني

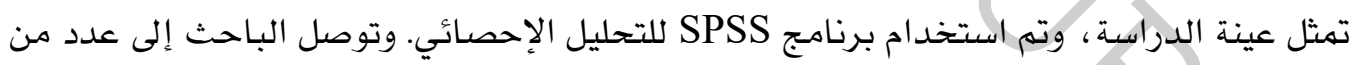

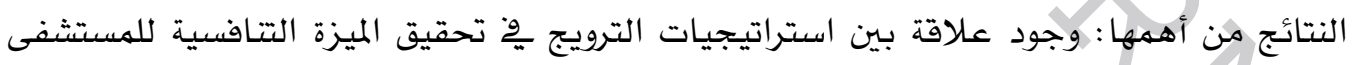
الإسـلامي يخ مدينة عمان. 


\section{منهجية البحث}

بعد مراجعة الدارسات السـابقة حول موضوع البحث، وجهمع البيانات والمعلومات من مصادرها الأولية والثانوية وتحليل المحتوى المعلوماتي للأسئلة التي تم توزيعها على عينة الدراسة، وومن أجل تحقيق أغراض الدراسة قام الباحث باستخدام المنهج الوصفي التحليلي الذي يعتبر أكثر المناهـج ملاءمة لهذه الدراسة، وذلك لسهولة استخدامه يُّ جهع البيانات من عدد كبير من مستهلكين شركة فاين. طرق جمع البيانات

اعتمد الباحث يْ هذه الدراسـة على مصدرين للحصول على البيانات وهما المصادر الثانوية الذي تعد بهثابة المصدر الأساسي يّْ تطوير وبناء الإطار النظري للدراسة، والمصادر الأولية التي تتمثل بالبيانات التي تم جمعها من خلال الاستبانة وذلك لمعالجة الجوانب التحليلية والإحصائية لموضوع الدراسة، ونستعرض فيها يلي بعض المصادر الأولية والمصادر الثانوية التي استخدمت

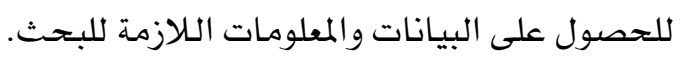

1. المصادر الأولية: اعتمد الباحث على جهع البيانات الأولية، من خلال إعداد وتصهيم استبانة، كأداة رئيسية للبحث ، ومعالجة الجوانب التحليلية لموضوع البحث، وتطوير هذه الاستبانة كمصدر أساسي للحصول على البيانات المتعلقة بأبعاد المتفيرات المستقلة، وهي عبارة عن واقع استخدام الترويج وأثره يِّ تعزيز الميزة التتافسية لشركة فاين لصناعة الورق الصحي (الإعلان، البيع الثخصي، العلاقات العامة، تتشيط المبيعات)، ومتغير الدراسة التابع (الميزة التتافسية) من خلال الفقرات المخصصة لكل متفير منها.

2. المصادر الثانوية: تعد بهثابة البيانات الأسـاسية ِِّ إعداد الإطار النظري للبحث، وتشهل كافة المعلومات التي تم الحصول عليها من كافة المصادر مثل الكتب والمراجع العربية والأجنبية ورسائل الماجستير التي لها علاقة بالبحث، وكذلك الدوريات والتقارير العامة والخاصة، والدراسـات السـابقة التي تتاولت موضوع الدراسة.

مجتمع الدراسة وعينتها

تكون مجتمع الدراسة من جميع مستهلكين منتجات شركة فاين لصناعة الورق الصحي موْ العاصمة عمان، والذي بلغ عدد سكانها اربعة ملايين نسمة (دائرة الاحصاءات العامة، ، 2015)، وقد تم اختيار عينة عشوائية بسيطة مكونة من (600) مستهلك، حيث تم توزيع 
الاستبانات عليهم، حيث استرجع منها (520) استبانة بنسبة استرجاع بلفت (86\%)، وتم استبعاد

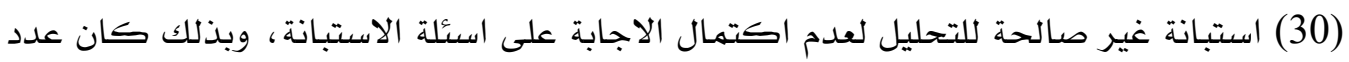

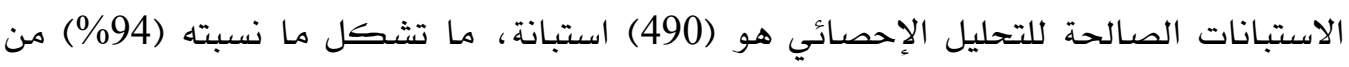

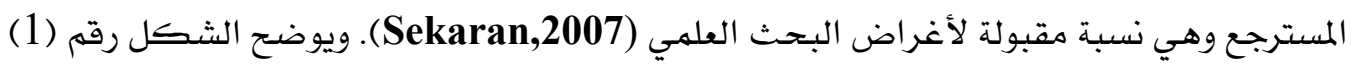
ذلك.

جدول (1) عدد الاستبانات الموزعة والمستردة والصالحة للتحليل الإحصائي

\begin{tabular}{|c|c|c|c|c|c|}
\hline \multicolumn{2}{|c|}{ الاستبانات الصالحة للتحليل } & \multicolumn{2}{|c|}{ الاستبانات المستردة } & \multicolumn{2}{|c|}{ عدد الاستبانات الموزعة } \\
\hline النسبة & 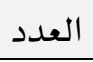 & 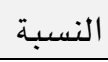 & العدد ال العد & 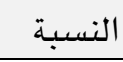 & 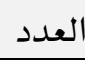 \\
\hline 94 & 490 & $86 \%$ & 205 & $100 \%$ & 600 \\
\hline
\end{tabular}

أداة الدراسة

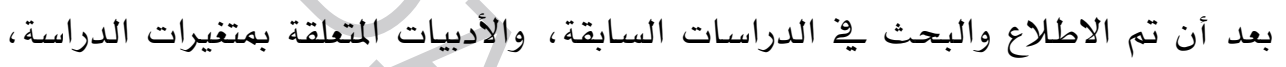

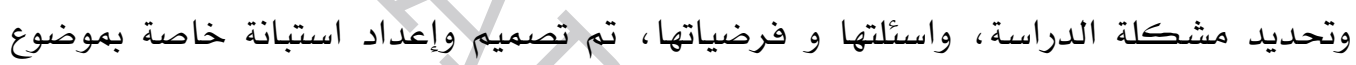

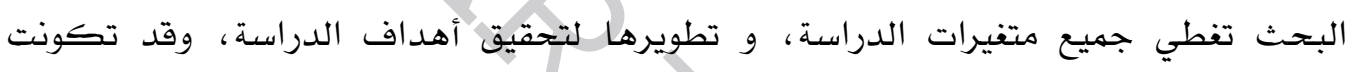

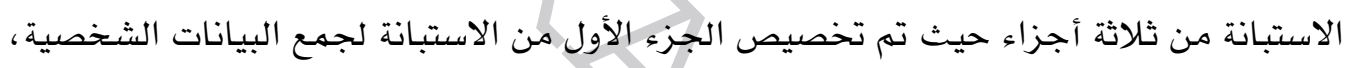

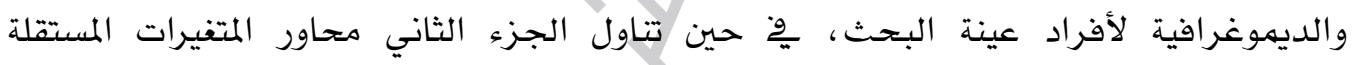

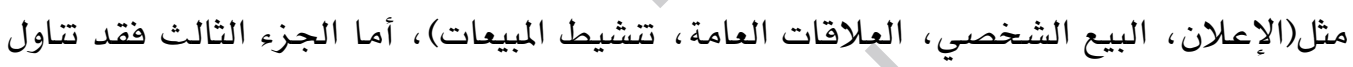

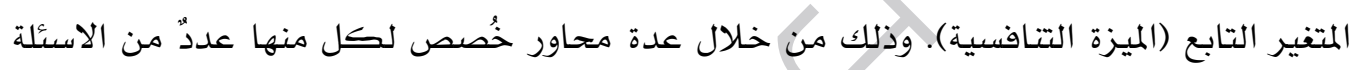
المحددة.

\section{مقياس أداء البحث}

قام الباحث باختيار مقياس ليكرت الخماسي (Likert Scale)، والذي يعتبر من أكثر

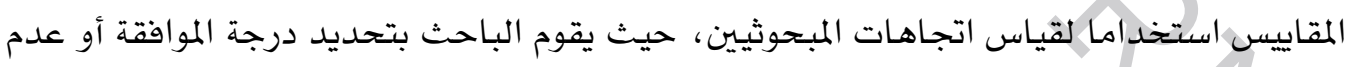

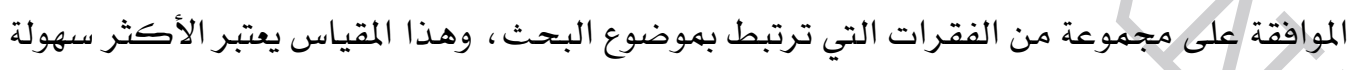

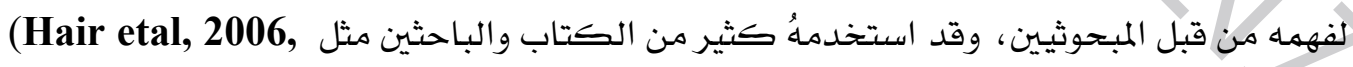

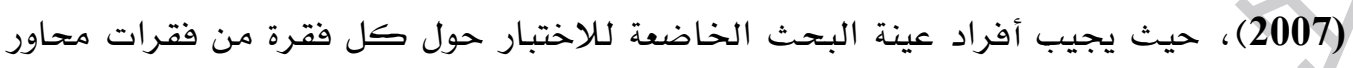

\begin{tabular}{|c|c|c|c|c|}
\hline لا أوافق بشدة & لا اوافق & محايد & أوافق & أوافق بشدة \\
\hline 1 | درجة & 2 درجة & 3 درجات & 4 درجات & 5درجات \\
\hline
\end{tabular}


من اجل التحقق من ثبات أداة الدراسـة تم إجراء اختبار معامـلات ألفا كرونباخ ونسبة الثبات (مدى الاتسـاق الداخلي لفقرات الاستبانة)، بحسب معامل (كرونباخ الفا)، الذي يشير إلى قوة

الارتباط و التماسك بين اسئلة البحث ، وكانت النتائج تظهر كما ِِّ الجدول رقم (1) الجدول (2): نتائج اختبار اداة البحث الذي يتكون من (الاتساق الداخلي لفقرات الاستبانة)

\begin{tabular}{|c|c|c|}
\hline الفا كرونباخ & عدد الفقرات & متغيرات الدراسة \\
\hline 0.822 & 5 & الإعلان \\
\hline 0.788 & 6 & البيع الشخصى \\
\hline 0.782 & 7 & العلاقات العامة \\
\hline 0.711 & 5 & تتشيط المبيعات \\
\hline 0.841 & 6 & الميزة التتافسية \\
\hline
\end{tabular}

تشير النتائج من خلال الجدول السابق (1) أن قيمة معامل ألفا كـرونباخ مرتفعة لكل متغير من متغيرات الاستبانة، وتترواح بين(0.822، 0.788، 0.782، 0.711، 0.841). كما أن قيمة معامل ألفا كرونباخ لجميع متفيرات الإستبانة كانت (مرتقعة) وهي توضح أن معامل الثبات مرتفع، وتكون الإستبانة وِّ شكلها النهائية قابلة للتوزيع. بعد ذلك تحقق الباحث من ثبات وصدق استبانة الدراسة مها يجعلة على ثقة كاملة بصحة الاستبانة وصلاحيتها لاستخراج النتائج النهائية واختبار الفرضيات (Pallant,2006).

\section{المتوسطات الحسابية والانحرافات المعيارية لمتفيرات الدراسة}

يوضح الجدول رقم (3) أدناه المتوسطات الحسابية والانحرافات المعيارية لكل متغيرات البحث ، حيث تبين من خلال نتائج التحليل الإحصائي بحصول المتغير التابع (الميزة التتافسية) على المرتبة (الأولى) من حيث الأهمية لأفراد عينة الدراسة، وجاء المتفير (الإعلان) على المرتبة الثانية ، وحصل متفير (البيع الثخصي) على المرتبة (الثالثة)، ـو حين جاء المتفير (العلاقات العامه) بو المرتبة (الرابعة)، وأخيرا حصل تتشيط المبيعات على المرتبة (الخامسة).

جدول رقم (3)

\begin{tabular}{|c|c|c|c|c|c|}
\hline درجة الموافقة & الانحراف المعياري & المتوسط الحسابي & محاور المزيج الترويجي & الرقم & الرتبة \\
\hline مرتفع & 0.756 & 0.803 & الإعلان & 1 & 2 \\
\hline مرتفع & 0.708 & 0.733 & البيع الشخصي & 2 & 3 \\
\hline متوسط & 0.862 & 0.253 & تتشيط المبيعات & 3 & 5 \\
\hline متوسطة & 0.955 & 0.733 & العلاقات العامة & 4 & 4 \\
\hline مرتفع & 0.606 & 3.95 & الميزة التتافسية & 5 & 1 \\
\hline
\end{tabular}




\section{تحليل الارتباط (Person correlation)}

تم تطبيق تحليل علاقة الارتباط بين عوامل الدراسة بهدف معرفة العلاقة الارتباطية بين

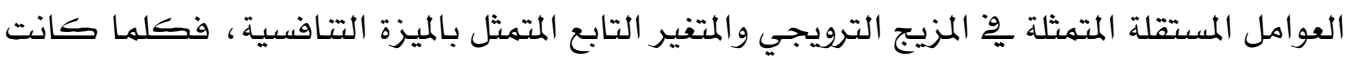
أثر الارتباط بين المتغيرات قريبة من الواحد الصحيح فإن ذلك يوضح أن أثر الارتباط قوية بين العوامل وكلما قلت درجة الارتباط عن الواحد الصحيح فإن ذلك يعني ضعف الأثر بين عوامل الدراسة ، وقد يكون العلاقة طردية أو عكسية، وِّْ النهاية تعتبر الأثر ضعيفة إذا كانت قيمة معامل الارتباط اقل من (0.30) وكذلك يمكن اعتبارها متوسطة إذا تراوحت قيهة الارتباط بهم (0.30-0.70) أها إذا كانت قيمة الارتباط أكثر من (0.70) توضح أثر قوية بين المتغيرات Hair )

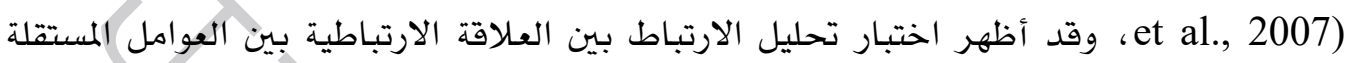

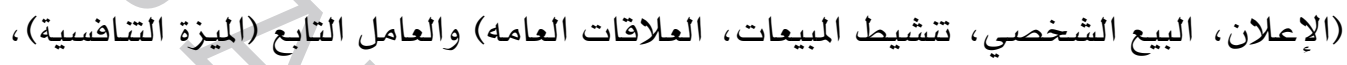

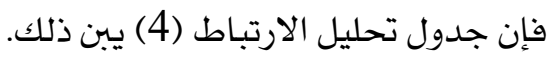

\begin{tabular}{|c|c|c|c|c|c|}
\hline العلاقات العمـه & تنشيط المبيعات & البيع الشخصي & الإعلان & الميزة التتافسية & المتفيرات \\
\hline 0.784 & 0.707 & 0.628 & 0.826 & 1 & الميزة التتافسية \\
\hline 0.624 & 0.602 & 0.528 & 1 & 0.826 & الإعلان \\
\hline 0.628 & 0.550 & 1 & 0.528 & 0.628 & البيع الشخصي \\
\hline 0.653 & 1 & 0.550 & 0.602 & 0.767 & تشيط المبيعات \\
\hline 1 & 0.653 & 0.628 & 0.624 & 0.784 & العلاقات العامة \\
\hline
\end{tabular}

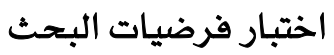

بعد ما تأكدنا من أن بيانات البحث قابلة للخضوع لتحليل الانحدار الخطي، أظهر ذلك من

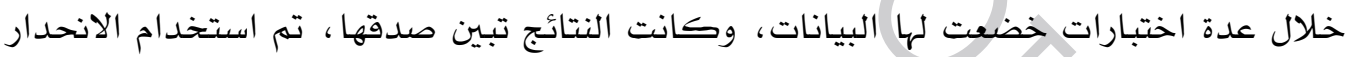
الخطي المتعدد لإثبات الفرضيات، ومعرفة مدى تأثير العوامل المستقلة مجتمعة مع بعضها بعضًا على المتغير التابع. استخدام تحليل الانحدار المتعدد أظهر الجدول رقم (5) نتائج اختبار الانحدار المتعدد الذي تم استخدامه لقياس أثر العوامل

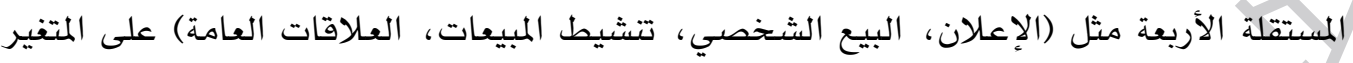

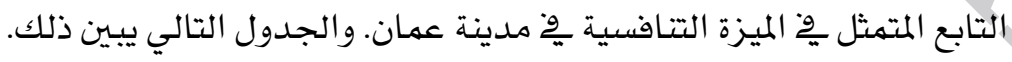


جدول رقم (5) نتائج اختبار الانحدار المتعدد للمتفيرات المستقلة الاربعة على الميزة التتافسية

\begin{tabular}{|c|c|c|c|c|}
\hline الدلالة الإحصائية & Beta & قيمة T المحسوبة & معامل الانحدار (B) & العوامل المستقلة \\
\hline 0.000 & 0.449 & 19.396 & 0.341 & الإعلان \\
\hline 0.010 & 0.058 & 2.569 & 0.051 & البيع الشخصي \\
\hline 0.000 & 0.277 & 11.564 & 0.346 & تتشيط المبيعات \\
\hline 0.000 & 0.286 & 11.098 & 0.305 & العلاقات العامة \\
\hline
\end{tabular}

$\mathrm{F}=740.828, \mathrm{P}=0.000, \mathrm{R}=0.919, \mathrm{Adj} . \mathrm{R}$ square $=0.844$

يبين من خلال النتائج الدالة يِّ الجدول رقم (5) مايلي: ثبوت الدلالة الإحصائية لمعملات الانحدار(B) لأربعة من المتفيرات المؤثرة هي (الإعلان، البيع الشخصي، تتشيط المبيعات، العلاقات العامه)، وهذا يعني وجود أثر قوي ذو دلالة إحصائية عند مستوى المعنوية(0.05)

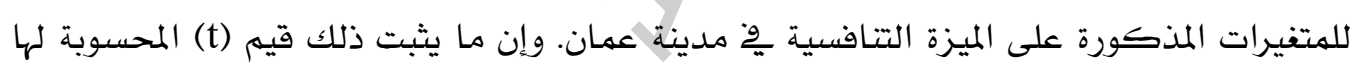
والبالغة (19.396, 2.569, 11.564, 11.098) على التوالي، وجميعها أكبر من قيمة (t) الجدولية البالغة (1.96)، وكذلك أن قيم الدلالة الإحصائية (Sig) للمتغيرات السابقة أقل من مستوى المعنوية (Sekran, 2007 (0.05). على ضوء النتائج السابقة التي ظهر من خلال التحليل الاحصائي تم رفضهما للفرضية العدم (H0)، وقبول الفرضية البديلة (H1) ومفادها يوجد أثر ذو دلالة إحصائية عند مستوى الدلالة المعنوية (0.05) للهتغيرات المؤثرة بدلالة أربعة من متغيراتها المتمثلة (الإعلان، البيع الشخصي، تتشيط المبيعات، العلاقات العامه) على الميزة التتافسية بِّ مدينة 
النتائج

بعد الانتهاء من التحليل الإحصائي، توصل الباحث إلى مجموعة من النتائج حول تأثير المزيج الترويجي على الميزة التنافسية لدى المستهلك الأردني يٌ مدينه عمان بالتطبيق على شركة فاين لصناعة الورق الصحي وفيها يلي خلاصة هذه النتائج بشقيها النظري والميداني 1. أظهر البحت بشكل واضح أن تأثير الإعلان على الميزة التتافسية من خلال الإعلانات المتكررة بشكل كبير من قبل شركة فاين يحافظ على الميزة التنافسية وخاصة عندما تقوم الشركة بالتركيز على المستهلك للمنتجات التي تتتجها الشركة.

2. بين البحث أن كثافة الإعلان المقدم من شركة فاين يؤدي الفرض المطلوب، وهذا كفيل بدعم الموقف التتافسي للشركة وتملك المستهلك للمنتجات الجديدة.

3. أظهر البحث أن شركة فاين تقوم مِّ تخفيض أسعار منتجاتها وتقدم منتجات مجانية لنشيط مبيعاتها بهدف تعريف المستهلك وإعطاء الثقة وِّ المنتجات المقدمة من قبل الشركة وتشجعها

لامتالك منتجاتها.

4. بين البحت أن رجال البيع يقومون بالرد على جميع استقسارات الزبون من خلال وسـائل الاتصال

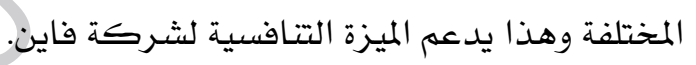

5. أظهر البحث أن رجال البيع ٍِِ الشركة يهتلكون الصفات والمؤهـات اللازمة التي تساعد على الترويج الجيد للمنتجات التي تتتجها شركة فاين لإقناع المستهلكين بجدوى استخدامها وهذا يبين استخدام البيع المباشر من خلال كفاءة رجال البيع.

6. اكتشف البحث أن العلاقات العامة تقوم بإنشاء علاقات تواصل مستهر مع الزبون وتساهم مِ تشكيل صورة ذهنية طيبة تخص الشركة ومنتجاتها وهذا الهدف الحقيقي الذي تسعى إلية

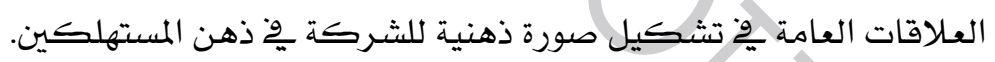
7. أظهر البحث أن شـركة فاين تعمل باستمرار على تحسـين منتجاتها وتطويرها بما يتلاءم مع متغيرات المنافسة المحلية والعالمية وتهتلك الشركة علامة تجارية قوية تلاقي اهتمام واضح من

المستهلكين.

8. وجود أثر ذي دلالة إحصائية عند مستوى الدلالة (a 1 (a 0.50) للمزيج الترويجي المتمثلة (الإعلان، البيع الشخصي، تنشيط المبيعات، العلاقات العامة) على تعزيز الميزة التتافسية لشركة فاين لصناعة الورق الصحي. 
التوصيات

من خلال ما تقدم ذكره سـابقا من النتائج خرجت الدراسـة بالعديد من التوصيات من أهمها: 1. التركيز على استخدام استراتيجيات الترويج لأنها تؤثر بشكل مباشر على عملية جذب

المستهلكين وزيادة الحصة السوقية والمحافظة على الميزة التتافسية لشركة.

يجب على الشركة الاهتمام يٌّ تطوير وتقديم منتجات جديدة ذات جودة عالية لكسب الميزة

التنافسية والمحافظة على الزبون.

3. ضرورة الاهتهام والتركيز على الإعلان وإعطائه الفرصة المناسبة وِ الاستراتيجيات

الترويجية والانشطة التي تقوم بها الشركة من أجل جذب المستهلك لمنتجات الشـركة.

4. توظيف رجال بيع مؤهلين ومتخصصسين ِِّ مجال التسويق وتزويدهم بهعلومات فنية حول منتجات الشركة من خلال تدريبهم عن طريق إعطائهم محاضرات تركز على منتجات الشـركة.

5. إعطاء الشركة أهمية كبيرة لدراسة وتحليل المنافسين وِّ المنطقة باعتبارها أحد المؤثرات 2

البيئة الخارجية التي تؤثر على درجة نجاح استراتيجيتها.

\section{الخاتمة}

نلاحظ مها سبق أن الترويج يهثل المرآة العاكسـة للثركة ومنتجاتها من خلال تعاون وتفاعل الشركة مع بيئتها الداخلية والخارجية من خلال أدوات كثيرة ومتتوعة لكل واحدةٍ منها خصائصها الفريدة، وكذلك يؤدي الترويج وظيفة أساسية وهي إقناع المستهلك المستهدف و إعلامـا والتأثير عليه ليتبنىّ موقفا إيجابيا تجاه الرسالة الإعلانية وما تعرضه من معلومات عن منتجات الشركة، اذا أدرك المستهلك المستهدف من الرسالة الإعلانية بنفس المعنى الذي قصد مرسل الرسالة، فإن الترويج حقق أهدافه. يْ النهاية ذلك أن غالبية الشركات ومن ضهنها شركة فاين تسعى إلى تحقيق نجاح عملياتها وتحاول باستمرار بناء موقع تتافسي فريد من نوعاه، يتمثل ِوِ البناء التطوير وتحسـين الأداء وِّ ظل البيئة التي تعهل فيها الشركة. ولغرض تحقيق هذه الأهداف فإن الأمر يتطلب من هذه الشركات امتلاك استراتيجية طويلة الأمد، وعدم النظر إلى تحقيق الربح يخ الوقت الآني فقط، وإنها عليها أن تفكر بشكل دقيق وشامل بالطريقة التي ستكون عليها هذه الأنثطة ِِّ مجال جني الأرباح ِِّ المستقبل، ولذلك فإن عملية التفكير الاستراتيجي للشركة وتحليل عوامل البيئة المؤثرة يخ عملياتها هي جوهر عملية المنافسة بين الشركات. 
المراجع العربية

- البكري، ثامر (2006)، "الاتصالات التسويقية والترويج" ، عمان .دار الحامد للنشر. - الضمور، هاني (2008)، تسويق الخدمات .عمان :دار وائل للنشر. - ابو فارة، يوسف احمد (2005)، النشاط الترويجي يخ البيئة الفندقية، مجلة اقتصاديات

شمال افريقيا ، جامعة حسيبة بن بو علي، الثلف، العدد 3 - ابو عمرة ، رامي (2011)، واقع الممارسات الترويجية لشركات التأمين يخ قطاع غزة واثرها على رضا العهـلاء، رسـالة ماجستير منشورة، الجامعة الإسـلامية، غزة. - احمد عوض الله رزق الله (2012) ، أثر الترويج على سلوك المستهلك النهائي، رسـالة ماجستير

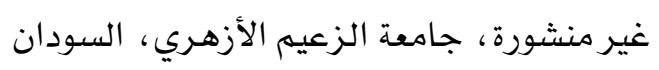
بوخنون، يهينه (2013)، دور الاعلان بِ ترويج المبيعات، رسالة منشورة، جامعة بسكرة، الجززائر سمية ، حجوطي (2012)، تتشيط المبيعات ودورها يِّ الأثير على القرار الشـرائي للمستهلك، رسالة ماجستير، المركز الجامعي. - احسن، العايب(2009)، دور الترويج مِّ تسويق الخدمات الفندقية ، رسـالة ماجستير منشورة، جامعة سكيكده، الجزائر - أمينة ، حماني (2012)، أثر الاتصالات التسويقية الالكترونية ِِّ استقطاب السياح، رسالة ماجستير منشورة ، جامعة الجزائر. - ابو عمرة، رامي (2012)، واقع الممارسات الترويجية لشركات التأمين مِ قطاع غزة وأثرها

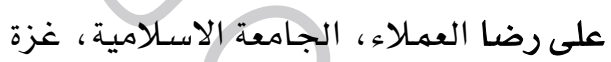
- الضمور، هاني، الشريدة، محمد تركي (2008)، "تأثير عناصر المزيج الترويجي على قرارات- المستهلك الأردني يِّ استخدام خدمة الهاتف الخلوي :دراسة تحليلية"، المجلة الأردنية قوْ إدارة الأعمال، المجلد ع ، العدد 4 توفيق، محمد عبدالمحسن، (2005)، بحوث التسويق وتحديات المنافسة الدولية ، دار الفكر العربي. شيماء الفاتح محمد، (2012)، أثر الترويج على سلوك المستهلك، رسالة ماجستير غير

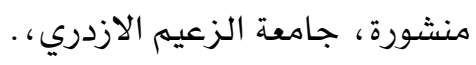
صبرة، سمير .(2010).مبادئ التسويق :مدخل معاصر، الطبعة الأولى، عمان، دار الإعصار العلهي للنشر والتوزيع. 
- طحطوح، مسعود (2009)، أهمية التسويق پِ تعزيز الميزة التتافسية للمؤسسة، رسالة ماجستير منشورة، جامعة الحاج لخضر - بانتة- الجزائر - عبد الهادي، عدلي، والبهنسى، محمد، والدرايسة، محمد، والنادي، نور الدين .(2011). الإعلان التقليدي والالكتروني، الطبعة الثانية، عمان، مكتبة المجتهع العربي للنشر والتوزيع.

عبود ، حسن، (2016) دور عناصر المزيج الترويجي وِّ التخفيف من الاثار السلبية للأزمات على المنتج السياحي، دراسة ميدانية على المنتج السياحي ٍِّ محافظة اللاذقية، رسالة ماجستير منشورة، جامعة تشرين/سوريا لمائ عبدالهادي، حسني (2018)، أثر استراتيجيات الترويج وِّ تحقيق الميزة التافسية، رسـالة منشورة، جامعة الزرقاء، الاردن عزام، زكريا ، وحسونة، عبد الباسط، والشيخ، مصطفى .(2008) .مبادئ التسويق الحديث بين النظرية والتطبيق، الطبعة الأولى، عمان :دار الميسرة للنشر والتوزيع والطباعة - قاقي، كريهة (2015)، دور التسويق الفندقي مخ تحقيق رضا الزبون، رسالة ماجستير منشورة، جامعة محمد خيضر - بسكرة، الجزائر. - قريشي، محمد ، (2010)، اهمية مصادر الميزة التافسية وِ المنظمة لضمان استمراريتها ومزاياها التنافسية. مجلة الواحات للبحوث والدراسـات، العدد 10 - منال، كباب (2007)، دور استراتيجية الترويج وِّ تحسين القدرة التسافسية للمؤسسة الوطنية، رسالة منشورة، جامعة محمد بوضياف بالمسية ، الجزائر. مرعوش، إكرام .(2009).مدى تأثير الإعلان على سلوك المستهلك، رسالة ماجستير، جامعة الحاج لخضر باتتة. ناصر حهود ، (2006) دور السياسات الترويجية بِّ تسويق المنتجات الدوائية السورية ، دراسة ميدانية عن شركات الأدوية السورية، مجلة جامعة تشرين للدراسات والبحوث العلمية، سلسلة العلوم الاقتصادية والقانونية المجلد 22، العدد الثاني. 


\section{References}

- Graham, A., \& Fill, B. (2007). Marketing communications. Amsterdam: Elsevier.

- Hair, J, Money, A., Samouel, F., \& Page, M, (2007). Research method of business. London John Wiley and Sonsltd, Chichester.

- Kotler, P., \& Keller, K. (2006). Marketing management. (12 ${ }^{\text {th }}$ Ed.) New Jersey: Prentice Hall.

- Kotler, P., \& Gary, A. ( 2005). Marketing: An introduction. ( $7^{\text {th }}$ Ed.). New Jersey: Prentice Hall.

- Kotler, P, (2004). Principles of management. New Jersey: Prentice Hall.

- Pallant, J. (2007). SPSS survival manual: A step by step guide to data analysis using SPSS for windows: Crows Vest: Allen and Unwin.

- Pettitt, S., \& Brassingtun, F. (2005). Essential of marketing. Harlow: Pearson education.

- Sekaran, U. (2006). Research methods for business: A skill building approach. New Delhi: Wiley India.

- Sekaran, U. (2007). Research methods for business: A skill-building approach ( $4^{\text {th }}$ Ed.). New Delhi: John Wiley and sons.

- Stimpson, P. (2002). Business studies. Cambridge: The press Syndicate of University, 

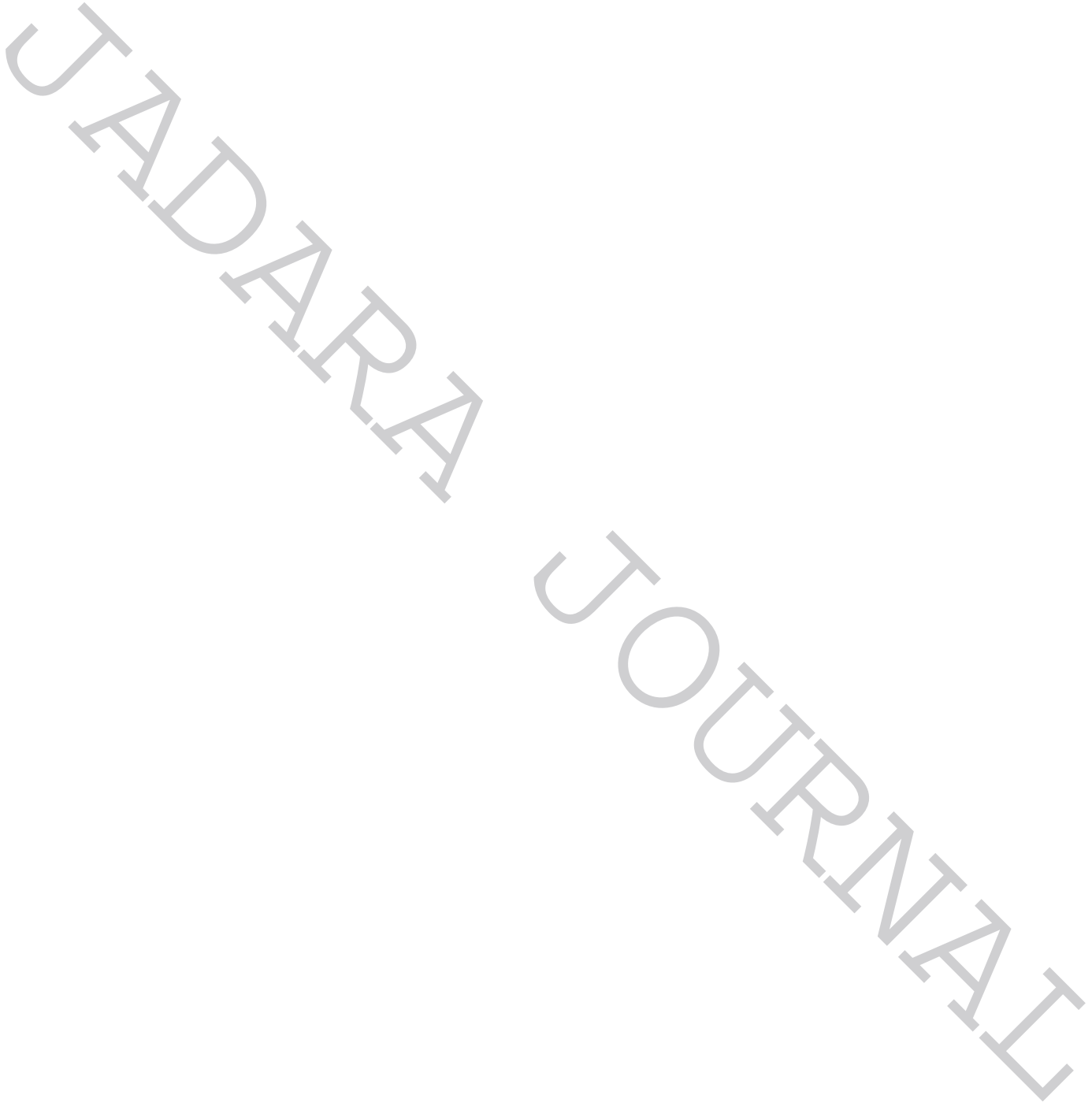